\title{
Prognostic value of blood cell count-derived ratios in BRAF-mutated metastatic melanoma
}

\author{
Jindrich Kopeckya, Ondrej Kubecek', Peter Priestera , Hana Vosmikovab ${ }^{b}$ Eva Cermakovac, Aneta Kyllarova ${ }^{a}$
}

Background. The treatment and prognosis of metastatic melanoma have changed during the last decade to include immunotherapy or targeted therapy as standard therapeutic options for BRAF-mutated melanoma. However, predictive and/or prognostic markers are lacking, especially in clinical situations where several options are available. The aim of this study was to determine the association of pre-therapeutic blood cell count-derived ratios (BCDR) with survival in patients with BRAF-mutated metastatic melanoma.

Methods. We evaluated the prognostic role of BCDR in therapy-naïve patients with BRAF-mutated metastatic melanoma treated with immune checkpoint inhibitors or targeted therapy. The impact of BCDR on survival was analysed using univariate and multivariate Cox proportional hazard models.

Results. We enrolled 46 patients treated with BRAF inhibitors and 20 patients who received anti-PD- 1 checkpoint inhibitors. The median progression-free survival (PFS) and overall survival (OS) were 8.3 and 18.2 months, respectively, with no statistical difference between groups. The objective response rate was $39 \%$ (30\% in the anti-PD- 1 and $44 \%$ in the targeted therapy groups). Baseline BCDR values were associated with improved PFS and OS in the immunotherapy group. Only the platelet-to-lymphocyte ratio (PLR) was associated with OS and PFS in the targeted therapy group. Independent prognostic indicators for PFS were lactate dehydrogenase, PLR and the lymphocyte-to-monocyte ratio (LMR) and those for OS were LMR, toxicity and the number of initial metastases.

Conclusion. BCDR had a substantial prognostic value in patients with BRAF-mutated metastatic melanoma treated with immune checkpoint inhibitors. However, a prognostic role for BCDR seemed less apparent in patients treated with targeted therapies.

Key words: melanoma, immunotherapy, targeted therapy, prognostic factors

Received: April 18, 2021; Revised: June 22, 2021; Accepted: August 11, 2021; Available online: August 24, 2021

https://doi.org/10.5507/bp.2021.053

(c) 2022 The Authors; https://creativecommons.org/licenses/by/4.0/

${ }^{a}$ Department of Oncology and Radiotherapy, University Hospital and Faculty of Medicine in Hradec Kralove, Charles University, Hradec Kralove, Czech Republic

${ }^{b}$ The Fingerland Department of Pathology, University Hospital and Faculty of Medicine in Hradec Kralove, Charles University, Hradec Kralove, Czech Republic

'Department of Medical Biophysics, Faculty of Medicine in Hradec Kralove, Charles University, Hradec Kralove, Czech Republic Corresponding author: Jindrich Kopecky, e-mail:jindrich.kopecky@fnhk.cz

\section{INTRODUCTION}

Treatment of advanced/metastatic melanoma has dramatically changed during the last decade with the introduction of the immune-checkpoint inhibitors anti-CTLA-4 in 2010 (ref. $^{1}$ ) and later anti-PD-1 (ref. ${ }^{2,3}$ ). The subsequent introduction of selective inhibitors of the B-Raf proto-oncogene $B R A F$ (BRAFi), such as vemurafenib, dabrafenib, and encorafenib ${ }^{4-6}$, and their combination with mitogenactivated protein kinases (MEK) inhibitors, such as cobimetinib, trametinib, and binimetinib ${ }^{6-8}$, have opened up further targeted treatment possibilities for a group of melanoma patients with $B R A F$ mutations. These new therapeutics have significantly improved the prognosis of metastatic melanoma, but both immunotherapy and targeted approaches have their advantages and disadvantages.

The main benefit of targeted therapy lies in its rapid onset of action and robust objective response. However, a high percentage of treatment failure occurs due to acquired resistance ${ }^{9}$. By contrast, immunotherapy is effective regardless of the $B R A F$ mutational status ${ }^{10}$; however, it carries a possible risk of irreversible immune-related adverse events. Unfortunately, to date, no randomised clinical trials have answered the question regarding the optimal sequence of BRAF/MEK inhibitor therapy and immunotherapy. Furthermore, no predictive biomarkers have emerged to aid in the decision-making process in the treatment of $B R A F$-mutated melanoma.

Several studies conducted in recent years have identified different ratios derived from blood cell counts that can provide reliable prognostic information ${ }^{11-13}$. However, these studies, and especially those involving patients with melanoma, are usually performed in patients undergoing immunotherapy ${ }^{14-18}$. In general, these studies are also limited to investigations of the neutrophil-lymphocyte ratio (NLR), with little emphasis on the platelet-lymphocyte ratio (PLR), the lymphocyte-monocyte ratio (LMR) or 
the systemic inflammation index (SII) as prognostic indicators in advanced/metastatic melanoma. Even less is known about the association of all these blood cell countderived parameters in melanoma patients treated with BRAF inhibitors.

The aim of the present study was therefore to determine whether pre-therapeutic blood cell count-derived ratios are associated with PFS and OS in patients with $B R A F$-mutated melanoma treated either with immunotherapy or with BRAF/MEK inhibitors.

\section{METHODS}

\section{Patient selection}

This retrospective cohort study included all treatmentnaïve patients with metastatic malignant melanoma harbouring a $B R A F$ gene mutation and undergoing treatment either with anti-PD1 therapy or BRAF +/- MEK inhibitors at the University Hospital Hradec Kralove between October 2012 and October 2020. All included patients had available haematological values. Patients were treated until disease progression or unacceptable toxicity.

The study was conducted following the principles of the Declaration of Helsinki. Because of the retrospective nature of the study, patient consent for inclusion was waived. No additional investigations, apart from routine laboratory tests, were performed.

\section{Variables}

For all patients, complete blood count (white blood cell count [WBC], platelets count [PLT] absolute lymphocyte count [ALC], absolute neutrophil count [ANC], absolute monocyte count [AMC]) and clinical data were collected before the treatment initiation and again at twelve weeks after the start of therapy. The collected characteristics included age, sex, adjuvant treatment and metastatic characteristics (such as location and number of affected organs and serum lactate dehydrogenase [LDH] levels). Histopathologic studies of the primary tumour (histology and Breslow thickness [mm]) were recorded.

NLR was calculated as NLR=ANC/ALC. PLR was calculated as PLR=PLT/ALC. LMR was calculated as $\mathrm{LMR}=\mathrm{AMC} / \mathrm{ALC}$, and the systemic immune-inflammation index was calculated as $\mathrm{SII}=\mathrm{ANC} \times \mathrm{PLT} / \mathrm{ALC}$. Changes in NLR, PLR, LMR, and SII were assessed at week 12 as an increase (yes vs no) from the initial value.

\section{Treatments and radiologic assessments}

Drugs were administered orally at the recommended dosages (dabrafenib: $150 \mathrm{mg}$ b.i.d; Vemurafenib: $960 \mathrm{mg}$ b.i.d.; trametinib: $2 \mathrm{mg} /$ day; cobimetinib: $60 \mathrm{mg} /$ day, nivolumab $3 \mathrm{mg} / \mathrm{kg}$ or $240 \mathrm{mg}$ every 14 days and pembrolizumab $200 \mathrm{mg}$ every 21 days).

Tumours were assessed at baseline and then every 12 to 16 weeks. The clinical response was classified according to the Response Evaluation Criteria in Solid Tumours v1.1 (RECIST).

Progression-free survival (PFS) was calculated from the first cycle of treatment to disease progression, as documented by imaging, death (event) or last follow-up (censored). Overall survival (OS) was calculated from the first cycle of treatment to death (event) or last follow-up (censored). The cut-off date for analysis was 4 January 2021.

\section{Statistical analysis}

Descriptive statistics were used to summarise patient and treatment characteristics. The chi-square test or Fisher's exact test and Mann-Whitney test were used to compare patient baseline characteristics and the parameters between the patients treated with anti-PD1 and BRAF +/- MEK inhibitors.

Univariate and multivariate Cox proportional hazard models were used to investigate associations of NLR, PLR, LMR and SII (or their increase in time from weeks 1 to 12 ) with survival (PFS and OS), adjusted for baseline characteristics (therapy, gender, age, time to metastatic disease, histology, presence of initial metastatic disease, number of metastatic sites, LDH and presence of toxicity). Results were presented as hazard ratios (HR) with 95\% confidence intervals (CIs). The OS and PFS were assessed using Kaplan-Meier estimates.

Optimal thresholds for NLR, PLR, LMR and SII were determined in part based on accessible literature reviews ${ }^{11-13}$ and were correlated to optimal cut-off points based on results from the ROC curve. The NLR, PLR, LMR and SII cut-off values were 3, 2, 169 and 800, respectively.

A $P$ value of 0.05 or less was considered statistically significant.

\section{RESULTS}

\section{Patient characteristics}

Among the 120 patients treated for metastatic melanoma in the first-line setting, 66 patients harboured $B R A F$ mutations, and all those patients were included in our study. The majority of those patients (46 patients) were treated with either BRAFi (vemurafenib, dabrafenib - 23 patients) or a combination of BRAFi and MEK inhibitors (vemurafenib, cobimetinib, dabrafenib, trametinib - 23 patients). Twenty patients received anti-PD-1 checkpoint inhibitors (nivolumab, pembrolizumab) in the first-line setting.

The baseline patient characteristics are summarised in Table 1. The median age at first treatment was 66.5 years in both groups, and $56 \%$ of patients were male. The most frequent histological type was nodular melanoma. A total of 17 patients (26\%) had metastatic disease at initial diagnosis. Most of the patients (52\%) had two or three afflicted organs, with lymph nodes (47 patients), subcutaneous tissue (35 patients) and lungs (28 patients) as the three leading sites. Comparison of immunotherapy and targeted therapy revealed an imbalance only in the number of involved metastatic sites, which was higher in the subgroup of patients treated with BRAF +/- MEK inhibitors (see Table 1). 
Table 1. Basic characteristic of patients.

\begin{tabular}{|c|c|c|c|c|c|c|c|}
\hline \multirow[t]{2}{*}{ Baseline Characteristics } & \multicolumn{2}{|c|}{ All patients } & \multicolumn{2}{|c|}{$\begin{array}{l}\text { Patients with } \\
\text { anti-PD-1 therapy }\end{array}$} & \multicolumn{2}{|c|}{$\begin{array}{l}\text { Patient with BRAFi } \\
+/ \text { - MEKi therapy }\end{array}$} & \multirow[t]{2}{*}{$P$} \\
\hline & $\mathrm{n}=66$ & $(\%)$ & $\mathrm{n}=20$ & $(\%)$ & $\mathrm{n}=46$ & $(\%)$ & \\
\hline Age (median [range]); years & \multicolumn{2}{|c|}{$66.5[35-80]$} & \multicolumn{2}{|c|}{$66.5[35-80]$} & \multicolumn{2}{|c|}{$66.5[34-86]$} & $0.91^{*}$ \\
\hline \multicolumn{7}{|l|}{ Gender } & $1.0^{\dagger}$ \\
\hline Male & 37 & $(56)$ & 11 & $(55)$ & 26 & $(56)$ & \\
\hline Female & 29 & (44) & 9 & $(45)$ & 20 & (44) & \\
\hline \multicolumn{7}{|l|}{ Histology type of primary melanoma } & $0.16^{\dagger}$ \\
\hline Nodular & 35 & $(53)$ & 10 & $(50)$ & 25 & $(54)$ & \\
\hline Superficial & 8 & (12) & 5 & $(25)$ & 3 & (7) & \\
\hline Acral & 2 & (3) & 1 & $(5)$ & 1 & (2) & \\
\hline Mucosal & 1 & (2) & 0 & $(0)$ & 1 & (2) & \\
\hline Unknown or not evaluable & 20 & $(30)$ & 4 & (20) & 16 & $(35)$ & \\
\hline \multicolumn{8}{|l|}{ Breslow thickness of primary melanoma } \\
\hline (median [range];mm) & \multicolumn{2}{|c|}{$3.6[0.2-12]$} & \multicolumn{2}{|c|}{$3.8[0.2-12]$} & \multicolumn{2}{|c|}{$3.5[0.7-25]$} & $0.87^{*}$ \\
\hline Braf mutation V600 & & & & & & & $0.68^{\dagger}$ \\
\hline $\mathrm{E}$ & 51 & (77) & 15 & (75) & 36 & $(78)$ & \\
\hline $\mathrm{K}$ & 12 & (18) & 5 & $(25)$ & 7 & (16) & \\
\hline A & 2 & (3) & 0 & $(0)$ & 2 & (4) & \\
\hline $\mathrm{R}$ & 1 & (2) & 0 & $(0)$ & 1 & (2) & \\
\hline Adjuvant therapy & & & & & & & $0.027^{\dagger}$ \\
\hline YES & 15 & $(23)$ & 1 & (5) & 14 & $(30)$ & \\
\hline NO & 51 & (77) & 19 & (95) & 32 & (70) & \\
\hline Initial metastatic disease & & & & & & & $0.55^{\dagger}$ \\
\hline YES & 17 & $(26)$ & 4 & (20) & 13 & (28) & \\
\hline NO & 49 & $(74)$ & 16 & $(80)$ & 33 & (72) & \\
\hline Time to metastatic disease (median [range];months) & $18.2[0$ & 71.5] & 19.0 & 68.6] & 16.0 & 71.5] & $0.99^{\ddagger}$ \\
\hline Number of initial metastatic sites & & & & & & & $0.006^{\dagger}$ \\
\hline 1 & 16 & $(24)$ & 10 & $(50)$ & 6 & (13) & \\
\hline 2 to 3 & 34 & $(52)$ & 8 & $(40)$ & 26 & $(57)$ & \\
\hline 4 and more & 16 & (24) & 2 & (10) & 14 & (30) & \\
\hline Site of metastases & & & & & & & \\
\hline Lung & 28 & $(42)$ & 6 & $(30)$ & 22 & (48) & $0.28^{\dagger}$ \\
\hline Liver & 16 & (24) & 2 & (10) & 14 & (30) & $0.12^{\dagger}$ \\
\hline Lymphnode & 47 & (71) & 11 & (55) & 36 & (78) & $0.077^{\dagger}$ \\
\hline Subcutaneous tissue & 35 & (53) & 10 & (50) & 25 & (54) & $0.79^{\dagger}$ \\
\hline Brain & 7 & (11) & 0 & $(0)$ & 7 & (15) & $0.092^{\dagger}$ \\
\hline Bones & 12 & (18) & 2 & (10) & 10 & (22) & $0.32^{\dagger}$ \\
\hline Renal & 5 & $(8)$ & 0 & $(0)$ & 5 & (11) & $0.31^{\dagger}$ \\
\hline Spleen & 3 & $(5)$ & 1 & $(5)$ & 2 & (4) & $1.00^{\dagger}$ \\
\hline Other & 11 & (17) & 3 & (15) & 8 & (17) & $1.00^{\dagger}$ \\
\hline LDH elevation & & & & & & & $0.33^{\dagger}$ \\
\hline YES & 43 & $(65)$ & 12 & $(60)$ & 31 & (68) & \\
\hline NO & 14 & (21) & 6 & (30) & 8 & (17) & \\
\hline Not evaluable & 9 & (14) & 2 & $(10)$ & 7 & (15) & \\
\hline LDH (median, [range];ukat/L) & $4.7[2$. & 20.6] & 4.7[ & 20.6] & 4.8 & $9.4]$ & $0.42^{*}$ \\
\hline Toxicity & & & & & & & $0.06 \dagger$ \\
\hline YES & 38 & $(58)$ & 8 & $(40)$ & 30 & $(65)$ & \\
\hline NO & 28 & (42) & 12 & $(60)$ & 16 & (35) & \\
\hline Treatment after failure & & & & & & & $0.25^{\dagger}$ \\
\hline YES & 21 & $(32)$ & 4 & $(20)$ & 17 & $(37)$ & \\
\hline NO & 45 & (68) & 16 & $(80)$ & 29 & (63) & \\
\hline Following therapy & & & & & & & \\
\hline BRAF + MEK inhibitors & 4 & $(18)$ & 4 & $(100)$ & 0 & 0 & \\
\hline Ipilimumab & 7 & (33) & 0 & $(0)$ & 7 & (41) & \\
\hline Chemotherapy & 2 & (10) & 0 & (0) & 2 & (12) & \\
\hline Nivolumab + ipilimumab & 2 & (10) & 0 & (0) & 2 & (12) & \\
\hline Nivolumab & 6 & (29) & 0 & (0) & 6 & (35) & \\
\hline Best achieved response & & & & & & & $0.23^{\dagger}$ \\
\hline CR & 9 & (14) & 4 & $(20)$ & 5 & (11) & \\
\hline PR & 17 & (26) & 2 & (10) & 15 & (33) & \\
\hline SD & 16 & (24) & 6 & (30) & 10 & (22) & \\
\hline PD & 24 & (36) & 8 & (40) & 16 & (34) & \\
\hline
\end{tabular}

"Mann-Whitney Test, ${ }^{\dagger}$ Fisher exact test, ${ }^{\star}$ Logrank test; CR, Complete response; PR, Partial response; SD, Stable disease; PD, Progressive disease; BRAFi, B-Raf proto-oncogene inhibitor; MEK, Mitogen-activated protein kinases; PD-1, Program death 1. 

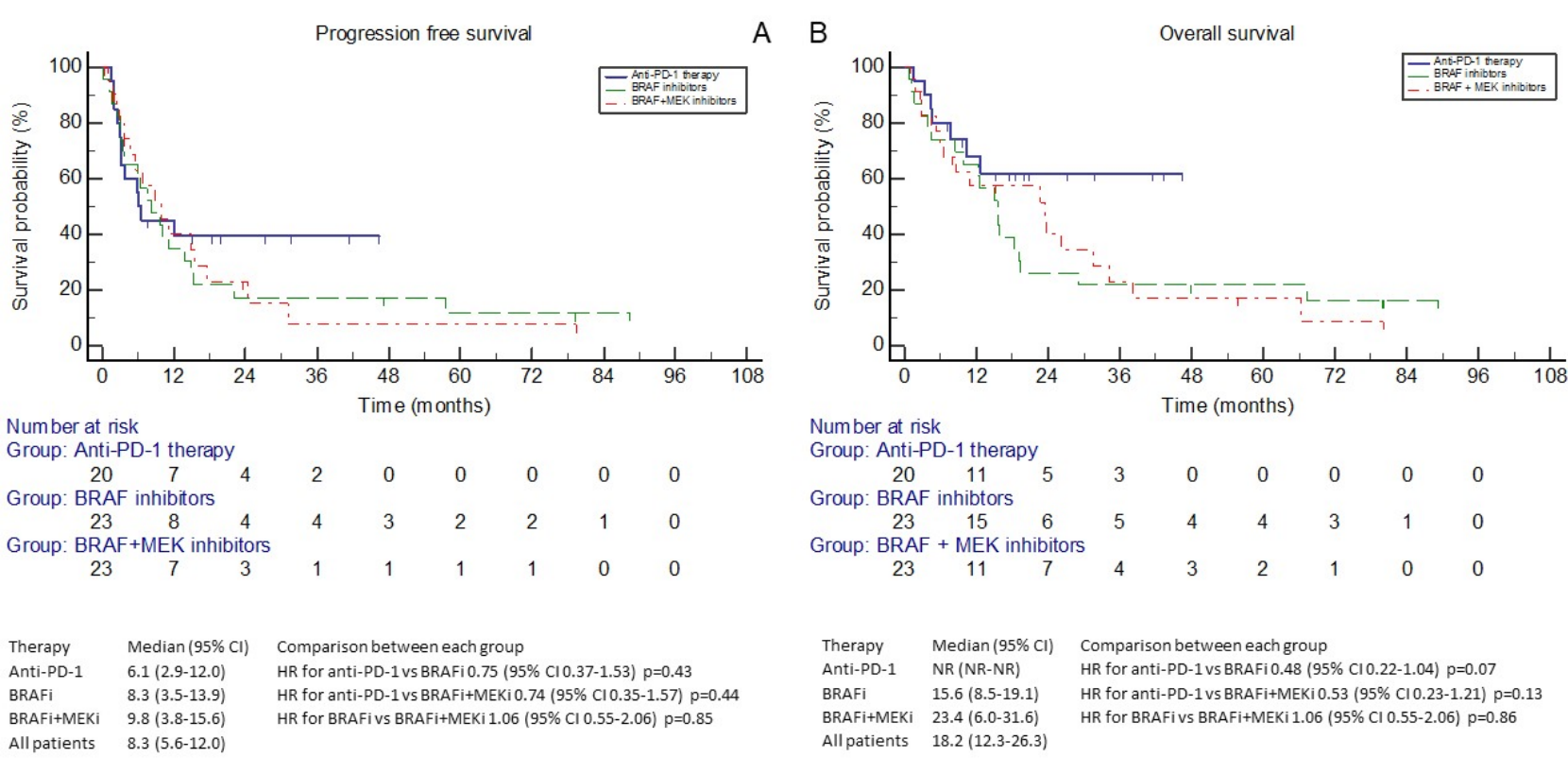

Fig. 1. Progression free survival (A) and Overall survival (B) based on therapy.

BRAFi, BRAF inhibitors; MEKi, MEK inhibitors; HR, hazard ratio; CI, confidential interval.

The median of follow-up was 19.1 (range 0.7-89.2) months. At the time of analysis, 23 patients were still alive (13 in the immunotherapy group and 10 in the targeted therapy group), and eight patients (6 in the immunotherapy group and 2 in the targeted therapy group) were still on therapy. The most frequent reason for therapy discontinuation was disease progression (12 patients in immunotherapy and 44 patients in targeted therapy group) and ten patients had to stop due to toxicity ( 2 in immunotherapy and 8 in the targeted therapy group).

The median PFS and OS for all patients were $8.3(95 \%$ CI: 5.6-12.0) and 18.2 (95\% CI: 12.3-26.3) months, respectively. Comparison of the three basic therapeutic approaches (anti-PD-1 versus BRAF monotherapy and BRAF plus MEK inhibition) revealed no statistical differences in PFS or OS. However, the median OS for antiPD-1 has not been reached, and a statistical trend was apparent for better OS in the immunotherapy group than in the BRAFi monotherapy group (Fig. 1).

Overall, nine patients (14\%) had a complete response (CR) (four in the anti-PD-1 group and five in the BRAF/ MEK therapy) and 17 patients (26\%) had a partial response (two in the anti-PD-1 group and fifteen in the targeted therapy group). Sixteen patients (24\%) had stable disease and 24 patients (36\%) had progressive disease (PD) Table 1. The objective response rate was 39\% (30\% in the anti-PD-1 therapy group and $44 \%$ in the targeted therapy group).

\section{Association of blood cell count-derived ratios and their changes with PFS and OS}

We transformed the continuous data into a dichotomous form by employing cut-off values. The distribution and frequency of the elevated and decreased cut-off values and their medians for every blood cell count-derived ratio are shown in Table 2. A significant difference was detect- ed between the immunotherapy group and the targeted therapy group regarding the frequency of lower and higher cut-off values for LMR and a borderline significant difference was detected for PLR. No differences were noted between patients with increases in NLR, PLR, LMR and SII levels from the first to the twelfth week. The increase in the baseline levels at the twelfth week had no impact on PFS or OS.

The NLR, PLR, LMR and SII values were strongly associated with the OS in both treatment groups. The baseline values under (NLR, PLR and SII) or above (LMR) the cut-off values were associated with improved survival. In the immunotherapy group, all the factors were significantly associated with PFS. However, PLR was the only factor that showed a statistically significant association with PFS in the subgroup of patients treated with targeted therapy (Fig. 2a-d).

No statistical differences were found between the blood count-derived ratios in the anti-PD-1 and BRAF/ MEK therapy groups. However, selection of the patients with worse prognosis based on blood count-derived ratios (i.e. those with NLR, PLR and SII above the cut-off values and with LMR below the cut-off value) resulted in a doubling of the median PFS in favour of targeted therapy over immunotherapy. By contrast, comparison of the two therapeutic approaches with low cut-off levels for NLR, PLR and SII and high LMR levels indicated that better results were achieved with immunotherapy.

\section{Blood cell count-derived ratios and their prognostic impact on survival}

The results of Cox univariate and multivariate analyses are presented in Tables 3 and 4. All blood cell countderived ratios had a statistically significant impact on PFS and OS according to the univariate analysis. We then performed a multivariate analysis for PFS and OS that 
Table 2. Blood cell count-derived ratio characteristics.

\begin{tabular}{|c|c|c|c|c|c|}
\hline & \multicolumn{2}{|c|}{$\begin{array}{c}\text { Patients with anti-PD-1 } \\
\text { therapy }\end{array}$} & \multicolumn{2}{|c|}{$\begin{array}{c}\text { Patient with BRAFi +/- } \\
\text { MEKi therapy }\end{array}$} & \multirow[t]{2}{*}{$P$} \\
\hline & $\mathrm{n}=20$ & $(\%)$ & $\mathrm{n}=46$ & $(\%)$ & \\
\hline \multicolumn{5}{|l|}{$\mathrm{NLR} \geq 3$} & $0.17^{\dagger}$ \\
\hline YES & 7 & $(35)$ & 27 & $(59)$ & \\
\hline NO & 12 & $(60)$ & 19 & (41) & \\
\hline Not evaluable & 1 & $(5)$ & 0 & $(0)$ & \\
\hline \multicolumn{5}{|l|}{ PLR $\geq 160$} & $0.054^{\dagger}$ \\
\hline YES & 6 & (30) & 28 & $(61)$ & \\
\hline NO & 13 & (65) & 18 & (39) & \\
\hline Not evaluable & 1 & $(5)$ & 0 & $(0)$ & \\
\hline \multicolumn{5}{|l|}{$\mathrm{LMR} \geq 2$} & $0.04^{\dagger}$ \\
\hline YES & 17 & $(85)$ & 28 & (61) & \\
\hline NO & 2 & (10) & 18 & (39) & \\
\hline Not evaluable & 1 & $(5)$ & 0 & $(0)$ & \\
\hline \multicolumn{5}{|l|}{$\mathrm{SII} \geq \mathbf{8 0 0}$} & $0.29^{\dagger}$ \\
\hline YES & 7 & (35) & 24 & $(52)$ & \\
\hline NO & 12 & $(60)$ & 22 & (48) & \\
\hline Not evaluable & 1 & $(5)$ & 0 & $(0)$ & \\
\hline \multicolumn{5}{|c|}{ Increase of NLR [ $1^{\text {st }}$ and $12^{\text {th }}$ week] } & $0.16^{\dagger}$ \\
\hline YES & 11 & (55) & 16 & (35) & \\
\hline NO & 7 & $(35)$ & 25 & $(54)$ & \\
\hline Not evaluable & 2 & $(10)$ & 5 & $(11)$ & \\
\hline \multicolumn{5}{|c|}{ Increase of PLR $\left[1^{\text {st }}\right.$ and $12^{\text {th }}$ week $]$} & $0.57^{\dagger}$ \\
\hline YES & 9 & $(45)$ & 16 & $(35)$ & \\
\hline NO & 9 & $(45)$ & 25 & $(54)$ & \\
\hline Not evaluable & 2 & $(10)$ & 5 & $(11)$ & \\
\hline \multicolumn{5}{|c|}{ Increase of LMR [ $1^{\text {st }}$ and $12^{\text {th }}$ week] } & $0.58^{\dagger}$ \\
\hline YES & 8 & $(40)$ & 22 & $(48)$ & \\
\hline NO & 10 & $(50)$ & 19 & $(41)$ & \\
\hline Not evaluable & 2 & $(10)$ & 5 & (11) & \\
\hline \multicolumn{5}{|c|}{ Increase of SII [ $1^{\text {st }}$ and $12^{\text {th }}$ week $]$} & $0.39^{\dagger}$ \\
\hline YES & 8 & $(40)$ & 13 & (28) & \\
\hline NO & 10 & $(50)$ & 28 & $(61)$ & \\
\hline Not evaluable & 2 & $(10)$ & 5 & $(11)$ & \\
\hline
\end{tabular}

"Mann-Whitney Test, †Fisher exact test; LMR, Lymphocyte-to-monocyte ratio; NLR, Neutrophil-lymphocyte ratio; PLR, Platelet-to-lymphocyte ratio; SII, Systemic inflammation index; BRAFi, B-Raf proto-oncogene inhibitor; MEK, Mitogen-activated protein kinases; PD-1, Program death 1.

included all blood cell count-derived ratios, together with age, gender, type of therapy, number of initial metastases, time to metastatic disease and LDH baseline levels. The presence of toxicity was added as another variable in the OS analysis. This analysis identified only elevated LDH level as an independent prognostic factor for inferior PFS, but it was not a prognostic factor for OS. The other independent parameters associated with PFS were PLR and LMR; NLR showed a borderline statistical significance (HR 2.13; 95\% CI: $0.99-4.56 ; P=0.05$ ). The only hematologic parameter associated with OS was LMR (HR 0.31; 95\% CI: $0.13-0.76 ; P=0.01$ ). Our analysis revealed toxicity and the number of initial metastases as the only other independent factors associated with OS (Table 4).

\section{DISCUSSION}

In recent years, the range of therapeutic options for melanoma has been dramatically improved and has moved metastatic melanoma from a fatal disease to, in some cases, a chronic disease. Today, the standard therapeutic strategy is to use either immunotherapy or, in the case of $B R A F$ mutant melanoma, targeted therapy ${ }^{19}$.

Although these approaches have shown promising results, a substantial portion of patients still do not respond well. Furthermore, these therapeutics have significant toxicity. Modern oncology tries to identify patients most likely to benefit from these types of therapies but, unfortunately, we do not have many predictive markers for melanoma therapy outcomes. To date, the only validated predictive marker is the $B R A F$ mutation ${ }^{20}$. However, we have several prognostic biomarkers for OS which might 
A
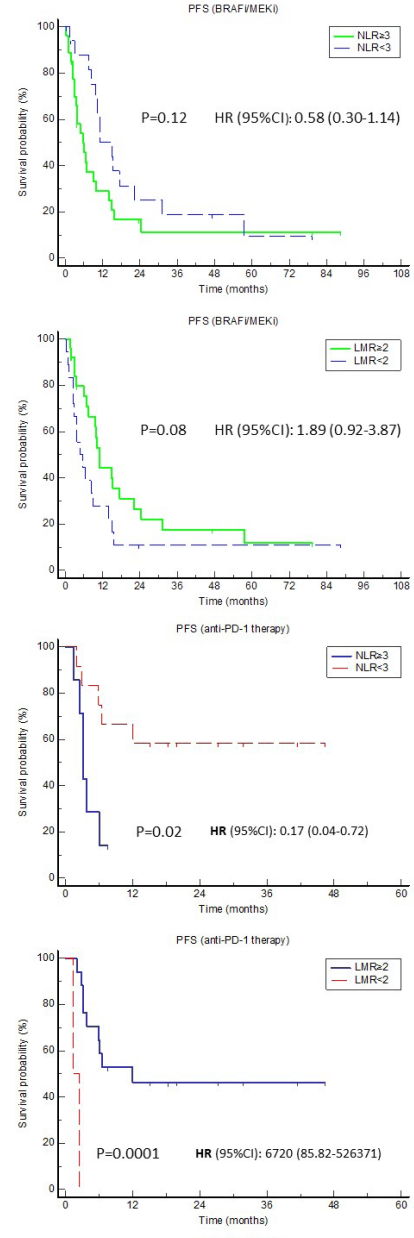

C
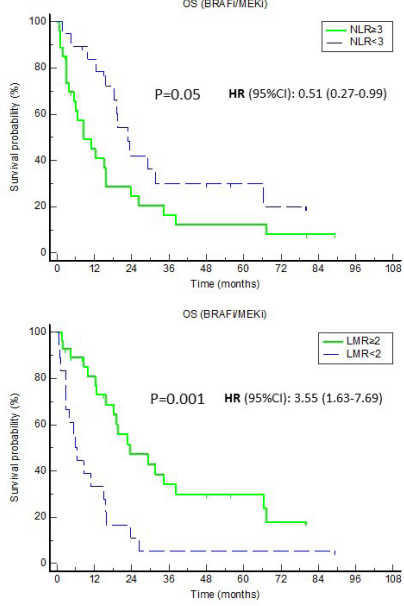

0

D
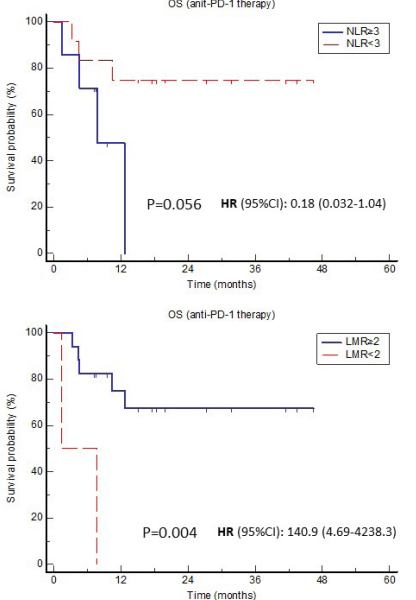
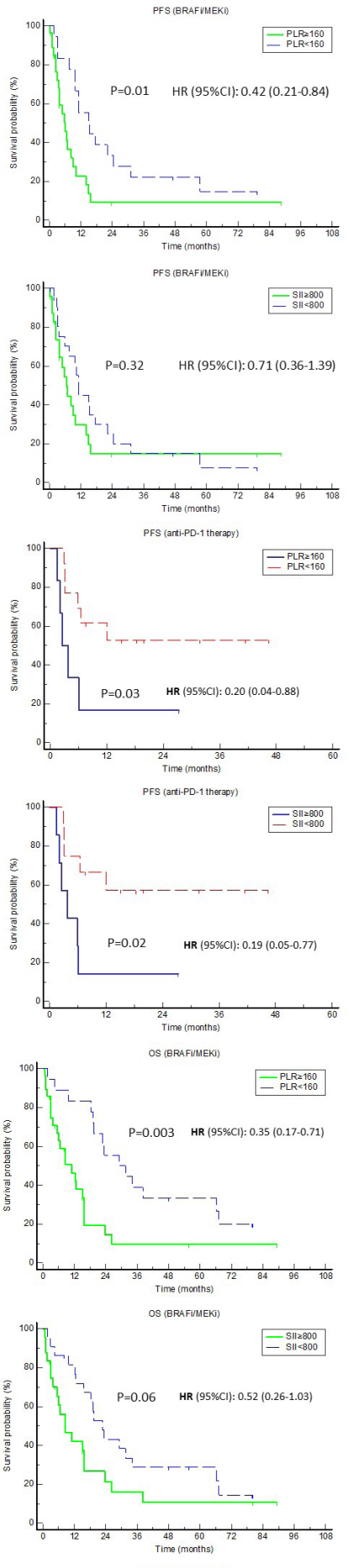

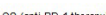
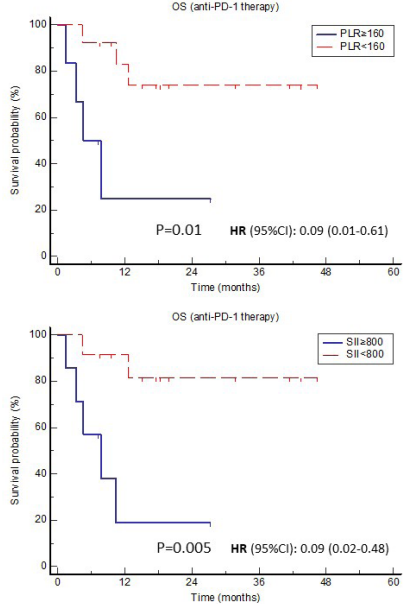

Fig. 2. Progression free survival for each blood cell count-derived ratio in patients with targeted therapy (A) and immunotherapy (B) and Overall survival for each blood cell count-derived ratio in patients with targeted therapy (C) and immunotherapy (D).

PFS, progression free survival; OS, overall survival; NLR, Neutrophil-to-lymphocyte ratio; PLR, Platelet-to-lymphocyte ratio; LMR, Lymphocyte-to-monocyte ratio; SII, Systemic inflammation index; HR, Hazard ratio; CI, confidential interval; BRAFi, BRAF inhibitors; MEKi, MEK inhibitors. 
Table 3. Univariate analysis.

\begin{tabular}{|c|c|c|c|c|c|c|}
\hline \multirow[b]{2}{*}{ Variable } & \multicolumn{3}{|c|}{ Progression free survival } & \multicolumn{3}{|c|}{ Overall survival } \\
\hline & HR & $95 \% \mathrm{CI}$ & $P$ & HR & $95 \% \mathrm{CI}$ & $P$ \\
\hline \multicolumn{7}{|l|}{ Age } \\
\hline$<65 / \geq 65$ & 1.02 & 0.58 to 1.84 & 0.92 & 0.84 & 0.45 to 1.58 & 0.59 \\
\hline \multicolumn{7}{|l|}{ Initial metastatic disease } \\
\hline Yes vs. No & 1.48 & 0.78 to 2.83 & 0.23 & 1.93 & 0.99 to 3.76 & 0.054 \\
\hline \multicolumn{7}{|l|}{ SII level } \\
\hline$\geq 800$ vs. $<800$ & 1.83 & 1.02 to 3.26 & 0.04 & 2.54 & 1.38 to 4.68 & 0.003 \\
\hline \multicolumn{7}{|l|}{ Gender } \\
\hline Female vs. Male & 1.12 & 0.63 to 1.99 & 0.69 & 0.85 & 0.46 to 1.57 & 0.61 \\
\hline \multicolumn{7}{|l|}{ Number of initial metastases } \\
\hline$\geq 3$ vs. $<3$ & 2.05 & 1.14 to 3.69 & 0.02 & 2.80 & 1.51 to 5.18 & 0.001 \\
\hline \multicolumn{7}{|l|}{ PLR level (cutoff 160) } \\
\hline$\geq 160$ vs. $<160$ & 2.48 & 1.37 to 4.48 & 0.003 & 3.27 & 1.73 to 6.17 & 0.0003 \\
\hline \multicolumn{7}{|l|}{ NLR level (cutoff 3) } \\
\hline$\geq 3$ vs. $<3$ & 2.36 & 1.30 to 4.29 & 0.005 & 2.63 & 1.41 to 4.93 & 0.003 \\
\hline \multicolumn{7}{|l|}{ Therapy } \\
\hline BRAFi +/- MEKi vs. anti-PD-1 & 1.34 & 0.69 to 2.58 & 0.39 & 2.09 & 0.92 to 4.71 & 0.077 \\
\hline \multicolumn{7}{|l|}{ LMR level (cutoff 2) } \\
\hline$\geq 2$ vs. $<2$ & 0.47 & 0.26 to 0.85 & 0.01 & 0.29 & 0.15 to 0.53 & 0.0001 \\
\hline \multicolumn{7}{|l|}{ LDH level baseline } \\
\hline$\geq 3,75$ vs. $<3,75$ & 1.12 & 1.04 to 1.19 & 0.001 & 1,16 & 1.08 to 1.25 & $<0.0001$ \\
\hline \multicolumn{7}{|l|}{ Histology } \\
\hline nodular vs other & 0.81 & 0.45 to 1.43 & 0.46 & 0.94 & 0.51 to 1.72 & 0.84 \\
\hline \multicolumn{7}{|l|}{ Time from diagnosis to metastasis } \\
\hline$<12$ vs. $\geq 12$ months & 1.10 & 0.62 to 1.97 & 0.75 & 1.21 & 0.66 to 2.22 & 0.55 \\
\hline \multicolumn{7}{|l|}{ Toxicity } \\
\hline Yes vs. No & 0.57 & 0.32 to 1.02 & 0.06 & 0.49 & 0.26 to 0.92 & 0.03 \\
\hline \multicolumn{7}{|l|}{ Change in SII } \\
\hline Yes vs. No & 1.25 & 0.66 to 2.38 & 0.49 & 1.31 & 0.66 to 2.61 & 0.44 \\
\hline \multicolumn{7}{|l|}{ Change in PLR } \\
\hline Yes vs. No & 1.12 & 0.60 to 2.08 & 0.72 & 1.35 & 0.70 to 2.58 & 0.37 \\
\hline \multicolumn{7}{|l|}{ Change in NLR } \\
\hline Yes vs. No & 1.28 & 0.69 to 2.38 & 0.44 & 1.14 & 0.59 to 2.18 & 0.69 \\
\hline \multicolumn{7}{|l|}{ Change in LMR } \\
\hline Yes vs. No & 0.82 & 0.44 to 1.52 & 0.53 & 0.81 & 0.42 to 1.55 & 0.52 \\
\hline
\end{tabular}

NLR, Neutrophil-to-lymphocyte ratio; PLR, Platelet-to-lymphocyte ratio; LMR, Lymphocyte-to-monocyte ratio; SII, Systemic inflammation index; HR, Hazard ratio; CI, Confidential interval; LDH, Lactate dehydrogenase; BRAFi, B-Raf proto-oncogene inhibitor; MEK, Mitogen-activated protein kinases; PD-1, Program death 1.

be informative and helpful in planning melanoma therapy. One of the earliest discovered and now the most used and well-established biomarker is LDH $\left(\right.$ ref. $\left.{ }^{20}\right)$.

An urgent need exists for predictive or at least prognostic markers in situations where multiple treatment options are available. This is especially true if the treatment choices include immunotherapy and targeted therapy, and it becomes even more prominent in countries where the use of drugs is limited or regulated. Therefore, the search must continue for new markers that will allow treatment of patients with the most effective therapy. The parameters obtained from peripheral blood are logical candidates as biomarkers to determine the possible outcome and to monitor treatment effectiveness. Their clear advantage lies in the simplicity of obtaining the required sample.
However, the ease of obtaining a sample is often nullified by the difficulty in interpreting the results.

Parameters such as NLR, PLR, LMR and SII are markers associated with the inflammatory process, and inflammation plays a key role in the pathophysiology of many diseases, including cancer ${ }^{21}$. Patients with advanced cancer usually show changes in peripheral blood cell composition that are suggestive of an expansion in the myeloid component (neutrophils, platelets, and monocytes) and a reduction in the lymphoid compartment ${ }^{22}$. These changes in peripheral blood reflect the situation in the tumour environment.

A common feature of cancer-associated chronic inflammation is neutrophilia, and its role in cancer pathogenesis is rather negative. Neutrophils have both 


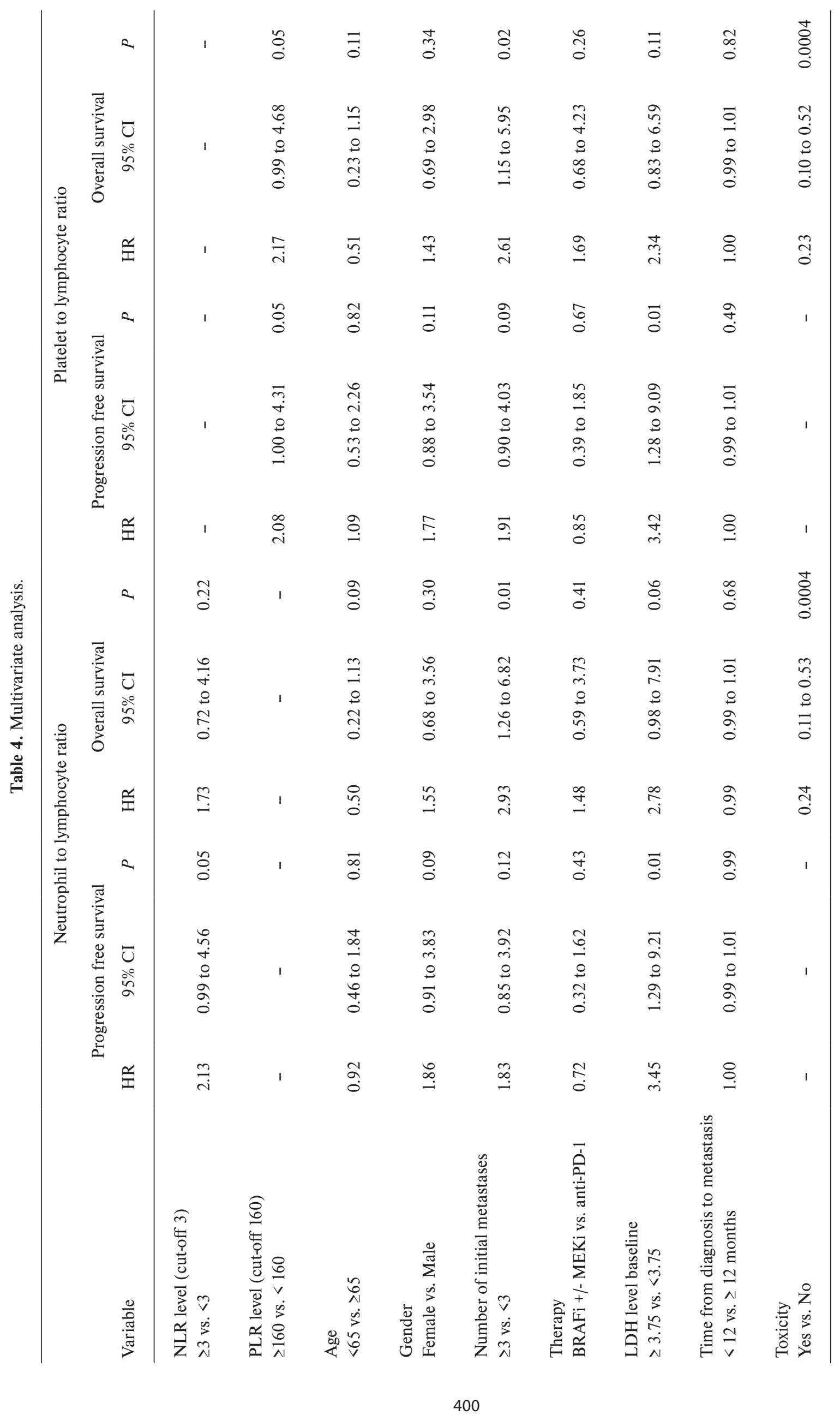




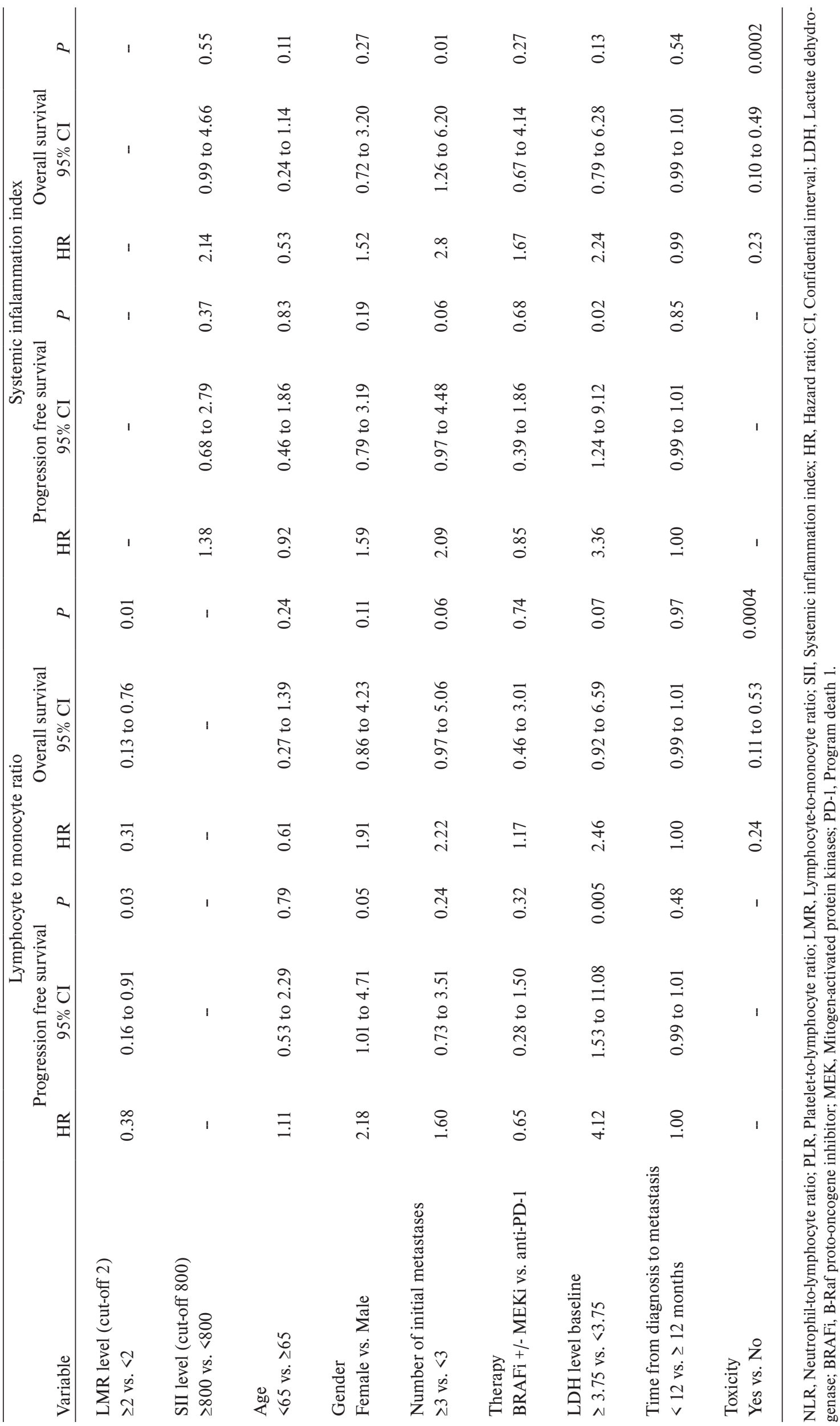


tumour-promoting and immune-suppressive roles and, together with the cytokines associated with tumour progression, neutrophils can suppress the activity of cytotoxic $\mathrm{T}$ cells and promote metastasis ${ }^{23}$. Some evidence indicates that platelets can guard tumour cells from immune elimination and promote tumour-cell transendothelial migration and metastasis. A variable secretion of growth factors by platelets could further support tumour growth, angiogenesis and metastasis ${ }^{24}$.

A similar ambivalent role in carcinogenesis is played by the various subsets of monocytes, which serve as a source of dendritic cells and tumour-associated macrophages (TAMs) $\left(\right.$ ref. $^{25}$ ). The TAMs are considered to promote tumorigenesis, thereby driving the negative outcome of various cancers ${ }^{26}$. By contrast, lymphocytes play an essential role in tumour-derived inflammatory responses, as these cells can induce antitumor activity with the help of cytotoxic cell death and the production of anti-proliferative cytotoxins. Relative lymphocytopenia therefore represents a significant decline in the cell-mediated adaptive immune response ${ }^{27}$.

The best studied blood cell count-derived ratio associated with metastatic melanoma has been the NLR. Its usefulness has been evaluated mostly for immunotherapy, including both anti-CTLA-4 (ref. ${ }^{14-16}$ ) and anti-PD-1 therapy $^{17,18}$ or for a combination of both drugs ${ }^{28}$. Other parameters (PLR, LMR and SII) and their association with survival are less well studied, particularly in melanoma ${ }^{29-31}$, and even fewer data are available regarding the usefulness of these ratios in metastatic melanoma patients treated with BRAF/MEK inhibitors, where again most information pertains to the NLR (ref. ${ }^{32-34}$ ). Our study confirmed the anticipated results for NLR and provided similar data for the rest of the blood cell count-derived ratios, where values above the cut-off for NLR, PLR and SII predicted reductions in OS and in PFS (ref. ${ }^{35-37}$ ). Conversely, for LMR, higher values were associated with better PFS and OS $\left(\right.$ ref. $\left.^{31}\right)$.

However, the results were not as promising for targeted therapy. This is the first study to address the impact of PLR, LMR and SII on the prognosis of patients treated with targeted therapy for metastatic melanoma. The only factor showing a statistically significant effect on PFS was the PLR. The other parameters, even the NLR, were of no prognostic value. The prognostic impact of targeted therapy on OS was statistically more evident, but still not as convincing as the prognostic impact seen for immunotherapy. In addition, the possibility remains that this association with OS might be biased by subsequent immunotherapy administration following targeted therapy failure. A marked disbalance in the disease burden between the immunotherapy and targeted therapy arm could provide another explanation, as the patients treated with targeted therapy showed a larger number of metastatic sites.

We were unable to find any statistical difference between blood cell count-derived ratios and their association with PFS and OS in the immunotherapy and targeted therapy groups, but we did observe that patients with prognostically unfavourable NLR, PLR, LMR and SII ratios showed better survival outcomes when treated with BRAF/MEK inhibitors than with immunotherapy. Our multivariate analysis identified other factors which could be useful as prognostic factors, such as the PLR and especially the LMR, which kept its significance in the multivariate analysis for both PFS and OS. However, the significance of the NLR as a prognostic factor was not sustained in the multivariate analysis.

The dynamics of the blood cell count-derived parameters can also be useful for predicting survival, as has been shown for metastatic renal cancer ${ }^{38}$, where dynamics evaluation proved to be an independent predictive and prognostic tool. However, the results are not that convincing for melanoma, as it is unclear if the absolute change or the relative change in blood cell count-derived ratios should be considered. Some melanoma studies have shown that an increase in the NLR of $\geq 30 \%$ after the initiation of therapy is associated with a shortened OS for immunotherapy ${ }^{14,17}$, but not for targeted therapy ${ }^{33}$. We did not observe any correlation between the change in blood cell count-derived ratios and survival for either immunotherapy or targeted therapy, even if we correlated these results with the percentage changes from the baseline values (data not shown).

Some aspects make the interpretation of our results challenging, particularly the retrospective nature of the study, the small number of patients and the variability of the cut-offs for each parameter. No validation studies have yet established the best fitting cut-off for NLR, PLR, LMR and SII in melanoma or any other cancer types. This is why these parameters are still not widely used in a daily praxis and why they remain experimental. We have therefore tried to combine a literature review of articles related to the cut-offs of blood cell count-derived ratios with statistical procedures, such as ROC analysis.

The imbalance in the number of metastatic sites between our two cohorts could have been another factor that affected our results. The real-world circumstances, such as the presence of systemic inflammation and the use of corticosteroids, were stated as potential confounding factors ${ }^{39}$. Our patient cohort, however, had used no corticosteroids and showed no signs of inflammation. Nevertheless, all these clinical situations have to be taken into consideration when interpreting the NLR, PLR, LMR and SII results.

Conversely, our study's strength is that it reflects the real-world therapy decision approach. In contrast to other clinical studies on $B R A F$ mutant melanomas, we included only treatment naïve patients to eliminate preceding therapy bias. This is the first study to evaluate all four blood cell count-derived ratios at the same time and in the same cohort of melanoma patients. To the best of our knowledge, this is also the first study to evaluate these parameters exclusively in $B R A F$ mutant melanomas and to compare their prognostic impact in a cohort of patients treated with immunotherapy and targeted therapy. 


\section{CONCLUSION}

Our results support a prognostic value of blood cell count-derived ratios (NLR, PLR, LMR and SII) in BRAF mutant metastatic melanoma patients treated with immune checkpoint inhibitors. However, the prognostic value of these parameters was less expressed in patients treated with targeted therapies. Therefore, the evaluation of baseline blood cell count-derived ratios should be considered in all patients treated with immunotherapy. Nevertheless, the knowledge of baseline values may aid in the decision-making process when both immunotherapy and targeted therapy are being considered as therapeutic options. Patients treated with BRAF/MEK inhibitors seem to have better prognosis than those on immunotherapy if the initial blood cell count-derived ratios are elevated (NLR, PLR and SII) or decreased (LMR). Larger prospective trials are warranted to make definitive conclusions regarding the prognostic significance of blood cell count-derived ratios in $B R A F$-mutated melanoma and to validate our proposed cut-off levels.

\section{ABBREVIATIONS}

ALC, Absolute lymphocyte count; AMC, Absolute monocyte count; ANC, Absolute neutrophil count; BCDR, Blood cell count-derived ratios; BRAF, B-Raf proto-oncogene; BRAFi, B-Raf proto-oncogene inhibitor; CIs, Confidence intervals; CR, Complete response; CTLA4, Cytotoxic T-lymphocyte antigen 4; HR, Hazard ratio; LDH, Lactate dehydrogenase; LMR, Lymphocyte-tomonocyte ratio; MEK, Mitogen-activated protein kinases; NLR, Neutrophil-lymphocyte ratio; OS, Overall survival; PD, Progressive disease; PD-1, Program death 1; PFS, Progression-free survival; PLR, Platelet-to-lymphocyte ratio; PLT, Platelets count; PR, Partial response; RECIST, Response Evaluation Criteria in Solid Tumours; SD, Stable disease; SII, Systemic inflammation index; TAMs, Tumour-associated macrophages; WBC, White blood cell count.

Acknowledgements: This work was supported by the Charles University Faculty of Medicine in Hradec Kralove grant Progress Q40/06 and Q40/11.

Author contributions: JK, OK: contributed to the study conception and design and they contributed equally to this study; JK, OK, PP, HV, AK: material preparation, data collection; EC, OK, JK: data analysis; All authors read and approved the final manuscript.

Conflicts of interest statement: The authors state that there are no conflicts of interest regarding the publication of this article.

\section{REFERENCES}

1 Hodi FS, O'Day SJ, McDermott DF, Weber RW, Sosman JA, Haanen JB, Gonzalez R, Robert C, Schadendorf D, Hassel JC, Akerley W, van den Eertwegh AJ, Lutzky J, Lorigan P, Vaubel JM, Linette GP, Hogg
D, Ottensmeier CH, Lebbe C, Peschel C, Quirt I, Clark JI, Wolchok JD, Weber JS, Tian J, Yellin MJ, Nichol GM, Hoos A, Urba WJ. Improved survival with ipilimumab in patients with metastatic melanoma. $\mathrm{N}$ Engl J Med 2010;363(8):711-23.

2 Larkin J, Chiarion-Sileni V, Gonzalez R, Grob JJ, Cowey CL, Lao CD, Schadendorf D, Dummer R, Smylie M, Rutkowski P, Ferrucci PF, Hill A, Wagstaff J, Carlino MS, Haanen JB, Maio M, Marquez-Rodas I, McArthur GA, Ascierto PA, Long GV, Callahan MK, Postow MA, Grossmann K, Sznol M, Dreno B, Bastholt L, Yang A, Rollin LM, Horak C, Hodi FS, Wolchok JD. Combined Nivolumab and Ipilimumab or Monotherapy in Untreated Melanoma. N Engl J Med 2015;373(1):2334.

3 Robert C, Schachter J, Long GV, Arance A, Grob JJ, Mortier L, Daud A, Carlino MS, McNeil C, Lotem M, Larkin J, Lorigan P, Neyns B, Blank CU, Hamid O, Mateus C, Shapira-Frommer R, Kosh M, Zhou H, Ibrahim $\mathrm{N}$, Ebbinghaus $\mathrm{S}$, Ribas A. Pembrolizumab versus Ipilimumab in Advanced Melanoma. N Engl J Med 2015;372(26):2521-32.

4 McArthur GA, Chapman PB, Robert C, Larkin J, Haanen JB, Dummer R, Ribas A, Hogg D, Hamid O, Ascierto PA, Garbe C, Testori A, Maio $M$, Lorigan $P$, Lebbé C, Jouary T, Schadendorf D, O'Day SJ, Kirkwood JM, Eggermont AM, Dréno B, Sosman JA, Flaherty KT, Yin M, Caro I, Cheng S, Trunzer K, Hauschild A. Safety and efficacy of vemurafenib in BRAF(V600E) and BRAF(V600K) mutation-positive melanoma (BRIM-3): extended follow-up of a phase 3, randomised, open-label study. Lancet Oncol 2014;15(3):323-32.

5 Hauschild A, Grob JJ, Demidov LV, Jouary T, Gutzmer R, Millward M, Rutkowski P, Blank CU, Miller WH, Jr., Kaempgen E, MartínAlgarra S, Karaszewska B, Mauch C, Chiarion-Sileni V, Martin AM, Swann S, Haney P, Mirakhur B, Guckert ME, Goodman V, Chapman PB. Dabrafenib in BRAF-mutated metastatic melanoma: a multicentre, open-label, phase 3 randomised controlled trial. Lancet 2012;380(9839):358-65.

6 Liszkay G, Gogas H, Mandalà M, Fernandez AMA, Garbe C, Schadendorf D, Dummer R, Ascierto PA, Robert C, Pickard MD, Sandor V, Gollerkeri A, Flaherty K. Update on overall survival in COLUMBUS: A randomized phase III trial of encorafenib (ENCO) plus binimetinib (BINI) versus vemurafenib (VEM) or ENCO in patients with BRAF V600-mutant melanoma. J Clin Oncol 2019;37(15_suppl):9512.

7 Robert C, Karaszewska B, Schachter J, Rutkowski P, Mackiewicz A, Stroiakovski D, Lichinitser M, Dummer R, Grange F, Mortier L, Chiarion-Sileni V, Drucis K, Krajsova I, Hauschild A, Lorigan P, Wolter P, Long GV, Flaherty K, Nathan P, Ribas A, Martin AM, Sun P, Crist W, Legos J, Rubin SD, Little SM, Schadendorf D. Improved overall survival in melanoma with combined dabrafenib and trametinib. N Engl J Med 2015;372(1):30-9.

8 Larkin J, Ascierto PA, Dreno B, Atkinson V, Liszkay G, Maio M, Mandala M, Demidov L, Stroyakovskiy D, Thomas L, de la CruzMerino L, Dutriaux C, Garbe C, Sovak MA, Chang I, Choong N, Hack SP, McArthur GA, Ribas A. Combined vemurafenib and cobimetinib in BRAF-mutated melanoma. N Engl J Med 2014;371(20):1867-76.

9 Proietti I, Skroza N, Bernardini N, Tolino E, Balduzzi V, Marchesiello A, Michelini S, Volpe S, Mambrin A, Mangino G, Romeo G, Maddalena P, Rees C, Potenza C. Mechanisms of Acquired BRAF Inhibitor Resistance in Melanoma: A Systematic Review. Cancers (Basel) 2020;12(10):2801. doi: 10.3390/cancers12102801

10 Larkin J, Lao CD, Urba WJ, McDermott DF, Horak C, Jiang J, Wolchok JD. Efficacy and Safety of Nivolumab in Patients With BRAF V600 Mutant and BRAFWild-Type Advanced Melanoma: A Pooled Analysis of 4 Clinical Trials. JAMA Oncol 2015;1(4):433-40.

11 Zhong JH, Huang DH, Chen ZY. Prognostic role of systemic immuneinflammation index in solid tumors: a systematic review and metaanalysis. Oncotarget 2017;8(43):75381-8.

12 Hu K, Lou L, Ye J, Zhang S. Prognostic role of the neutrophil-lymphocyte ratio in renal cell carcinoma: a meta-analysis. BMJ open 2015;5(4):e006404-e.

13 Wang Z, Peng S, Wang A, Xie H, Guo L, Jiang N, Niu Y. Plateletlymphocyte ratio acts as an independent predictor of prognosis in patients with renal cell carcinoma. Clinica Chimica Acta 2018;480:166-72.

14 Cassidy MR, Wolchok RE, Zheng J, Panageas KS, Wolchok JD, Coit D, Postow MA, Ariyan C. Neutrophil to Lymphocyte Ratio is Associated With Outcome During Ipilimumab Treatment. EBioMedicine 2017;18:56-61. 
15 Zaragoza J, Caille A, Beneton N, Bens G, Christiann F, Maillard H, Machet L. High neutrophil to lymphocyte ratio measured before starting ipilimumab treatment is associated with reduced overall survival in patients with melanoma. Br J Dermatol 2016;174(1):14651.

16 Ferrucci PF, Ascierto PA, Pigozzo J, Del Vecchio M, Maio M, Antonin Cappellini GC, Guidoboni M, Queirolo P, Savoia P, Mandalà M, Simeone E, Valpione S, Altomonte M, Spagnolo F, Cocorocchio E, Gandini S, Giannarelli D, Martinoli C. Baseline neutrophils and derived neutrophil-to-lymphocyte ratio: prognostic relevance in metastatic melanoma patients receiving ipilimumab. Ann Onco 2016;27(4):732-8.

17 Bartlett EK, Flynn JR, Panageas KS, Ferraro RA, Sta Cruz JM, Postow MA, Coit DG, Ariyan CE. High neutrophil-to-lymphocyte ratio (NLR) is associated with treatment failure and death in patients who have melanoma treated with PD-1 inhibitor monotherapy. Cancer 2020;126(1):76-85.

18 Fujisawa Y, Yoshino K, Otsuka A, Funakoshi T, Fujimura T, Yamamoto Y, Hata H, Tanaka R, Yamaguchi K, Nonomura Y, Hirai I, Furudate S, Okuhira H, Imafuku K, Aoki M, Matsushita S. Baseline neutrophil to lymphocyte ratio combined with serum lactate dehydrogenase level associated with outcome of nivolumab immunotherapy in a Japanese advanced melanoma population. Br J Dermatol 2018;179(1):213-5

19 Michielin O, van Akkooi ACJ, Ascierto PA, Dummer R, Keilholz U. Cutaneous melanoma: ESMO Clinical Practice Guidelines for diagnosis, treatment and follow-upt. Ann Oncol 2019;30(12):1884-901.

20 Tarhini A, Kudchadkar RR. Predictive and on-treatment monitoring biomarkers in advanced melanoma: Moving toward personalized medicine. Cancer Treatment Reviews 2018;71:8-18.

21 Coussens LM, Werb Z. Inflammation and cancer. Nature 2002;420(6917):860-7.

22 Cohen JT, Miner TJ, Vezeridis MP. Is the neutrophil-to-lymphocyte ratio a useful prognostic indicator in melanoma patients? Melanoma Manag 2020;7(3):Mmt47.

23 Uribe-Querol E, Rosales C. Neutrophils in Cancer: Two Sides of the Same Coin. J Immunol Res 2015;2015:983698.

24 Goubran HA, Burnouf T, Radosevic M, El-Ekiaby M. The plateletcancer loop. Eur J Intern Med 2013;24(5):393-400.

25 Engblom C, Pfirschke C, Pittet MJ. The role of myeloid cells in cancer therapies. Nat Rev Cancer 2016;16(7):447-62.

26 Olingy CE, Dinh HQ, Hedrick CC. Monocyte heterogeneity and functions in cancer. J Leukoc Biol 2019;106(2):309-22.

27 Smyth MJ, Dunn GP, Schreiber RD. Cancer immunosurveillance and immunoediting: the roles of immunity in suppressing tumor development and shaping tumor immunogenicity. Adv Immunol 2006;90:1-50.

28 Rosner S, Kwong E, Shoushtari AN, Friedman CF, Betof AS, Brady MS, Coit DG, Callahan MK, Wolchok JD, Chapman PB, Panageas KS, Postow MA. Peripheral blood clinical laboratory variables associated with outcomes following combination nivolumab and ipilimumab immunotherapy in melanoma. Cancer Med 2018;7(3):690-7.

29 Zhang F, Gong W. Prognostic Value of the Platelet-to-Lymphocyte Ratio in Patients With Melanoma: A Meta-Analysis. Front Oncol 2020;10:1116.

30 Martins SL, Miguel-Semedo P, Martins-Branco DA, Monteiro AM, Moreira CMA, Pais H, Vendrell I, Mansinho A, Gouveia EJ, Passos M-JS, Costa L, Sousa ART. Hematological profile: A prognosis tool in melanoma patients treated with immunotherapy. J Clin Oncol 2019;37(8_suppl):135.

31 lacono D, Basile D, Gerratana L, Vitale MG, Pelizzari G, Cinausero M, Poletto E, Puglisi F, Fasola G, Minisini AM. Prognostic role of disease extent and lymphocyte-monocyte ratio in advanced melanoma. Melanoma Res 2019;29(5):510-5.

32 Cocorocchio E, Martinoli C, Gandini S, Pala L, Conforti F, Stucchi S, Mazzarol G, Ferrucci P. Baseline neutrophil-to-lymphocyte ratio (NLR) is associated with outcome of patients treated with BRAF inhibitors. Clin Trans Oncol 2020;22(10):1818-24.

33 Finon A, Zaragoza J, Maillard H, Beneton N, Bens G, Samimi M, Caille A, Machet L. A high neutrophil to lymphocyte ratio prior to BRAF inhibitor treatment is a predictor of poor progression-free survival in patients with metastatic melanoma. Eur J Dermatol 2018;28(1):3843.

34 Teterycz P, Jagodzińska-Mucha P, Cybulska-Stopa B, Mariuk-Jarema A, Kozak K, Koseła-Paterczyk H, Czarnecka AM, Rajczykowski M, Dziura R, Galus Ł, Mackiewicz J, Świtaj T, Klimczak A, Falkowski S, Suwiński R, Ziobro M, Ługowska I, Rutkowski P. High baseline neutrophil-to-lymphocyte ratio predicts worse outcome in patients with metastatic BRAF-positive melanoma treated with BRAF and MEK inhibitors. Melanoma Res 2018;28(5):435-41.

35 Boissier R, Campagna J, Branger N, Karsenty G, Lechevallier E. The prognostic value of the neutrophil-lymphocyte ratio in renal oncology: A review. Urol Oncol 2017;35(4):135-41.

36 Dalpiaz O, Luef T, Seles M, Stotz M, Stojakovic T, Pummer K, Zigeuner R, Hutterer GC, Pichler M. Critical evaluation of the potential prognostic value of the pretreatment-derived neutrophil-lymphocyte ratio under consideration of $\mathrm{C}$-reactive protein levels in clear cell renal cell carcinoma. Br J Cancer 2017;116(1):85-90.

37 Wang X, Su S, Guo Y. The clinical use of the platelet to lymphocyte ratio and lymphocyte to monocyte ratio as prognostic factors in renal cell carcinoma: a systematic review and meta-analysis. Oncotarget 2017;8(48):84506-14.

38 Lolli C, Basso U, Derosa L, Scarpi E, Sava T, Santoni M, Crabb SJ, Massari F, Aieta M, Conteduca V, Maruzzo M, La Russa F, Wheater M, Berardi R, Galli L, De Giorgi U. Systemic immune-inflammation index predicts the clinical outcome in patients with metastatic renal cell cancer treated with sunitinib. Oncotarget 2016;7(34):54564-71.

39 Karakonstantis S, Kalemaki D, Tzagkarakis E, Lydakis C. Pitfalls in studies of eosinopenia and neutrophil-to-lymphocyte count ratio. Infect Dis (Lond) 2018;50(3):163-74. 